\title{
BIOSYNTHESIS OF SILVER NANOPARTICLES USING CYNARA SCOLYMUS, LAVANDULA ANGUSTIFOLIA, ALKANNA TINCTORIA AND ITS ANTIMICROBIAL ACTIVITIES-A COMPARATIVE STUDY
}

Javairia Mehboob ${ }^{1}$, Syeda Hafsa $\mathrm{Ali}^{1}{ }^{*}$, Fahima Ashraf Kasi ${ }^{1}$, Syeda Ayesha $\mathrm{Ali}^{2}$, Safa Farooqi ${ }^{3}$, Muneeza Arbab ${ }^{4}$,

\begin{abstract}
Nanotechnology is a promising field of science that implicates use of nano size particle which anchors a prominent place in various biomedical applications. Silver is known for its antimicrobial nature. This study elucidates the qualitative phytochemical properties of three plant extracts and utilizing it in biosynthesis of silver nanoparticles. Green Silver nanoparticles (AgNPs) were synthesized from $1 \mathrm{mM}$ Silver Nitrate $\left(\mathrm{AgNO}_{3}\right)$ solution incubated with leaf extracts of Cynara scolymus (Artichoke), Alkanna tinctoria (Alkanet), and Lavandula angustifolia (Lavender), respectively. The synthesized nanoparticles were characterized visually, UV-Vis spectrophotometer and using X-ray diffraction (XRD). We further determined antimicrobial activity of these biogenic nanoparticles against pathogenic bacterial strains (Staphylococcus aureus, and Escherichia coli) and Plant pathogenic fungal strains (Aspergillus flavus and Aspergillus niger). Our results confirmed the formation of AgNPs with size $<100 \mathrm{~nm}$. Antibacterial activity of lavender mediated AgNP was highly significant, followed by artichoke mediated AgNP and Alkanet AgNP. However, in contrast, Artichoke mediated AgNP showed significant activity against plant fungal strains, followed by Alkanet AgNP, and finally by Lavender mediated AgNPs. We concluded that the three plants have versatile biochemical molecules responsible for wide range of AgNP and its activity against bacterial and fungal strains. Studies on combined use of AgNPs with other antimicrobial agents may solve the problem of toxicity and possible risk of drug resistance.
\end{abstract}

KEYWORDS: Silver nanoparticles, Antimicrobial activity, Medicinal Plants, phytochemical contents

Citation: Mehboob , J.; S. H. Ali; F. Kasi; S.A. Ali; S.Farooqi; M.Arbab. 2021. Biosynthesis Of Silver Nanoparticles Using Cynara Scolymus, Lavandula Angustifolia, Alkanna Tinctoria and Its Antimicrobial Activities-A Comparative Study, Pakistan. Pak. J. Weed Sci. Res., 27 (3):277-295.

1.Department of Microbiology, Balochistan University Information Technology Engineering and Management Sciences, Quetta, Balochistan, Pakistan

2.Department of Biochemistry, Sardar Bahadur Khan Women University, Quetta, Balochistan, Pakistan

3.Department of Environmental Sciences, International Islamic University, Islamabad, Pakistan

4.Department of Biotechnology, Balochistan University Information Technology Engineering and Management Sciences, Quetta, Balochistan, Pakistan

*Corresponding author: syeda.hafsa@buitms.edu.pk 


\section{INTRODUCTION}

Nanotechnology is an interdisciplinary research area responsible for creating diverse nanomaterials with wide applications in pharmaceutics, medical sciences, drug and gene delivery, cosmetic industries, food industries, chemical industries, and space industries (Abdel-Aziz et al., 2014). Nanoparticles are known by their precise dimensions and accuracy. They have defined structures with sizes ranging from $1 \mathrm{~nm}$ to $100 \mathrm{~nm}$. Nanoparticles are attractive resources in creating novel structures and facilitating its incorporation into biological systems. The extraordinary surface area to volume ratio of nanoparticles enforces higher reactivity than macro-size particles. Biologically synthesized nanoparticles are dynamic and depend on type of plant species, plant parts (root, stem, leaf, seed, flower etc.). The plants are the reservoirs of many vital secondary metabolites such as alkaloids, flavonoids, terpenoids, tannins, phenols, saponins, proteins, carbohydrates, and oils. These molecules possess numerous therapeutic properties and antimicrobial activities (Jain et al., 2009). Metabolites extracted from plants act as reducing and stabilizing agents in the synthesis of nanoparticles. Plant mediated nanoparticles have high reputation in recent times due to their non-toxic nature, and high efficiency in biomedicines (Abdel-Aziz et al., 2014).

Silver nanoparticles (AgNPs) are recognized for their uniqueness and diverse properties such as optical features, chemical stability, good conductivity, catalytic activity, electrical and thermal properties enabling their incorporation into various products. Silver nanoparticles have widely been used as antimicrobials agents due to their biocidal effect against pathogenic microorganisms and responsible for disrupting their cytoplasmic membrane, disturbing their enzymatic activities leading to its destruction. The use of silver nanoparticles as antimicrobial coatings in many textiles and fabrics, such as wound dressings, topical creams, antiseptic sprays, and biomedical devices involves continuous release of silver ions in lower levels to protect against microbial infection (Iravani et al., 2014). Recently, plants are utilized in synthesizing nanoparticles by exploiting its secondary metabolites. In this study we comparatively analysed the antimicrobial activity of three biogenic silver nanoparticles using Cynara scolymus (Artichoke), Alkanna Tinctoria (Alkanet), and Lavandula angustifolia (Lavender) and tested its antibacterial activity ( $S$. aureus and $E$. coli) and antifungal activity ( $A$. niger and $A$. flavus).

\section{METHODOLOGY}

\section{Collection of Plant Materials}

Two medicinal plants Cynara scolymus (Artichoke) leaves, Lavandula angustifolia (Lavender) leaves and a weed Alkanna Tinctoria (Alkanet) leaves were obtained from Baluchistan Agriculture and Research Development Centre (BARDC) Quetta. The plants were washed thoroughly thrice with normal tap water to remove dust and soil residues and further washed using distilled water to remove remaining debris. The fresh and clean plants were shade dried for 10-15 days and then finely ground using pestle and mortal.

\section{Plant extract}

The leaves extract for each plant was prepared using 5 grams of dried powdered plant leaves separately in 100 $\mathrm{mL}$ Erlenmeyer flask containing $50 \mathrm{~mL}$ of distilled water. The flask was heated at $58-60^{\circ} \mathrm{C}$ temperature in water bath for approximately 5 hours before decanting it. The resulting solution was filtered using $0.45 \mu \mathrm{m}$ Whatman filter paper and the extract was cooled and stored at $4^{\circ} \mathrm{C}$ in fridge for future use (Qayyum et al., 2020).

\section{Detection of phytoconstituents:}

The qualitative detection of phytoconstituents present in the extracts was also performed using standard protocols (Banu et al., 2015) 
Detection of Oils and Resins: Spot test: The synthesized leave extracts for plants were applied individually on filter paper. The extracts were then allowed to settle on filter paper (Banu et al., 2015).

Test for Protein: Ninhydrin Test was used to estimate proteins. In controls extract was added with distilled water. About $2 \mathrm{ml}$ of respective extracts were treated with $0.2 \%$ Ninhydrin solution and heated for 5-10 minutes (Banu et al., 2015).

Test for Phenol: Ferric Chloride $\left(\mathrm{FeCl}_{3}\right)$ Test determines presence of phenol. The controls, containing plant extracts were treated with distilled water. About $2 \mathrm{ml}$ of the respective plant extract were treated with $2 \mathrm{ml}$ of distilled water followed by adding $10 \% \quad \mathrm{FeCl}_{3}$ solution into the mixture (Banu et al., 2015).

Test for Saponin: Foam Test: About $2 \mathrm{ml}$ of extract was taken in a test tube and 10 $\mathrm{ml}$ of distilled water was added and shaken vigorously (Banu et al., 2015).

Test for Tannin: $\mathrm{FeCl}_{3}$ Test: Around $2 \mathrm{ml}$ of $5 \% \mathrm{FeCl}_{3}$ solution was added in $2 \mathrm{ml}$ of plant extracts individually (Banu et al., 2015).

Detection of Flavonoids: Sulphuric Acid $\left(\mathrm{H}_{2} \mathrm{SO}_{4}\right)$ Test: Plant extracts were treated with few drops of concentrated $\mathrm{H}_{2} \mathrm{SO}_{4}$ (Banu et al., 2015).

Detection of Terpenoids: Salkowski $s$ Test: About $5 \mathrm{ml}$ of extract was mixed with two $\mathrm{ml}$ of chloroform and $3 \mathrm{ml}$ of concentrated $\mathrm{H}_{2} \mathrm{SO}_{4}$ to form a layer (Banu et al., 2015).

Test for Alkaloid: Hager's Test: To execute this test a saturated solution of picric acid was prepared and added carefully in respective plant extracts, the solutions were then allowed to settle down (Banu et al., 2015).

Test for carbohydrates: Benedict's Test: The three crude extracts when mixed with $2 \mathrm{ml}$ of Benedict's reagent and boiled until precipitates are formed (Banu et al., 2015).

\section{Synthesis of silver nanoparticle:}

Approximately, $1 \mathrm{mM}$ concentration of $\mathrm{AgNO}_{3}$ was used for synthesis of silver nanoparticles. To synthesize silver nanoparticles, $10 \mathrm{~mL}$ of the plant extract was taken in a burette and added drop by drop in $20 \mathrm{~mL}$ aqueous solution of $1 \mathrm{mM}$ $\mathrm{AgNO}_{3}$ in a beaker covered with aluminium foil to prevent photodegradation, while keeping the beaker on the magnetic stirrer at room temperature for 2 hours respectively. The same procedure was done for all three plants to synthesize nanoparticles.

\section{Characterization of Silver nanoparticles}

\section{Visual characterization}

The synthesized silver nanoparticles were monitored constantly to assure reduction of $\mathrm{Ag}+$ ions to $\mathrm{Ag}$ particles until the colour shifts was observed (Ahmed et al., 2016).

\section{UV-VIS Spectrophotometric analysis}

The final extract containing silver nanoparticles was characterized using UVVIS spectrophotometer (Jenway, Model no. 6305). The colloidal solution of silver nanoparticles was monitored at a wavelength ranging from $300-600 \mathrm{~nm}$. The initial and final reading was taken to ensure successful reduction of silver ion to silver particles (Ponarulselvam et al., 2012).

\section{X-Ray Diffraction}

The silver nanoparticles were also characterized using XRD (Bruker, $2^{\text {nd }}$ Generation, D2, and Phaser) which was conducted by Department of Petroleum and Gas Engineering BUITEMS. For XRD, dry powder of green nanoparticles was confirmed and matched with standard (JCPDS file No. 04-0783) of silver nanoparticles.

\section{Antibacterial activity}

The activity of all three biogenic silver nanoparticles were determined against gram-positive bacteria (Staphylococcus aureus) and gram- 
negative bacteria (Escherichia coli). The identified bacterial strains were obtained from Sardar Bahadur Khan Women University. The bacterial strains were inoculated with $10 \mathrm{~mL}$ of nutrient broth and incubated at $37^{\circ} \mathrm{C}$ for 24 hours. The inoculum grown overnight was matched with 0.5 McFarland solution and $100 \mu \mathrm{L}$ of respective bacterial strains containing $10^{5}$ $\mathrm{CFU} / \mathrm{mL}$ were cultured onto Müller-Hinton Agar (MHA). The activity of silver nanoparticles was identified using four wells onto the media plate. Each well containing $100 \mu \mathrm{L}(50 \mathrm{mg} / \mathrm{mL})$ of plant extract, $100 \mu \mathrm{L}$ of water distilled water, $100 \mu \mathrm{L}(1 \mathrm{mM}) \mathrm{AgNO}_{3}$ and $50 \mu \mathrm{L}(0.2 \mathrm{mM})$ silver nanoparticles, respectively. This method was repeated for all three biogenic AgNPs with three replicates in each batch. The plates were incubated at $37^{\circ} \mathrm{C}$ overnight and results were analysed after 18 hours of incubation (Gajbhiye et al., 2009). Zone of inhibition was measured in $\mathrm{cm}$ using a scale.

\section{Antifungal activity}

We further determined the antifungal activity of biogenic silver nanoparticles against plant pathogenic fungal strains (Aspergillus flavus and Aspergillus niger). The fungal strains were obtained from Agriculture College Quetta and cultured onto Potato-dextrose agar for 48 hours at $24^{\circ} \mathrm{C}$. The respective strain was picked and dissolve in $1 \mathrm{ml}$ sterile distilled water. About $50 \mu \mathrm{L}$ of respective fungal strains containing $10^{5} \mathrm{CFU} / \mathrm{mL}$ were cultured on Potato-Dextrose agar. To elucidate the activity of silver nanoparticle four wells were made with $100 \mu \mathrm{L}$ (50 $\mathrm{mg} / \mathrm{mL}$ ) plant extract, $100 \mu \mathrm{L}$ distilled water, $100 \mu \mathrm{L}(1 \mathrm{mM})$ silver nitrate and 50 $\mu \mathrm{L} \quad(0.2 \mathrm{mM})$ silver nanoparticles, respectively. The plates were incubated at $24^{\circ} \mathrm{C}$ overnight and results were checked after 48 hours of incubation. This process was repeated for each biogenic AgNP synthesized using Lavender, Artichoke, and Alkanet with each batch containing three replicates. The zone of inhibition was measured in $\mathrm{cm}$ using a scale.

\section{Statistical Analysis}

The results for the zone of inhibition for bacterial and fungal strains in $\mathrm{cm}$ were analysed using GraphPad prism. The data were expressed in mean \pm standard deviation (version 5.01).

\section{RESULTS AND DISCUSSION}

\section{Qualitative analysis of phytochemical constituents}

Plants are reservoirs of many essential metabolites. The presence of phytochemicals present in the extracts were analysed using different standard protocols. The oil and resin test were performed using spot tests by applying the extract on filter paper. The transparent colour was an indication of oil and resin in all the tested extracts (Banu et al., 2015) (See figure no. 1). Ninhydrin test confirmed the presence of proteins in the extracts. The extract's colour changed to dark blue which indicated the presence of proteins and amino acids (Banu et al., 2015) (See figure no. 2). $\mathrm{FeCl}_{3}$ test confirmed the presence of phenols in all extracts. The control extracts remained unchanged, while extracts treated with phenol transformed to bluish-black which implies the presence of phenols (Banu et al., 2015) (See figure no. 3). The foam test confirmed the occurrence of saponins in the respective extracts. Formation of foam upon shaking illustrated the presence of saponins while controls remain unchanged (Banu et al., 2015) (See figure no. 4). $\mathrm{FeCl}_{3}$ test confirmed the presence of tannins in the respective extracts. The extracts were positive for tannins as indicated by dark blue to greenish-black colour (Banu et al., 2015) (See figure no. 5). The presence of flavonoids was elucidated using a sulfuric acid test. The controls remained unchanged. Whereas the tested extracts showed positive results by changing the colour to dark orange (Banu et al., 2015) (See figure no. 6). These plant metabolites play vital role in reducing $\mathrm{Ag}$ ions into $\mathrm{Ag}$ particle. These components act as reducing and stabilizing agent which encapsulates the ions after the reaction. Salkowski's test confirmed the 
presence of terpenoids in the respective extracts. All the three tested extracts were positive as indicated by appearance of reddish-brown coloration at the interface (Banu et al., 2015) (See figure no. 7). Similarly, Hager's test confirmed the presence of alkaloids in the respective extracts as indicated by appearance of orange to yellow colour precipitates (Banu et al., 2015) (See figure no. 8). Benedict's test confirms the presence of carbohydrates in the respective extracts. The controls remained unchanged whereas the tested extracts were positive as indicated by appearance of greenishbrown color. (Banu et al., 2015) (See figure no. 9). Medicinal plants have been used for thousands of years and owe their importance in the field of research and medicine. They have been widely used as a traditional medicine to treat various infections. The effectiveness of medicinal plants is evident from their universal use. Nanoparticles are synthesized using medicinal plants are preferred due to their low-cost, eco-friendly, and non-toxic nature (Saji et al., 2010).
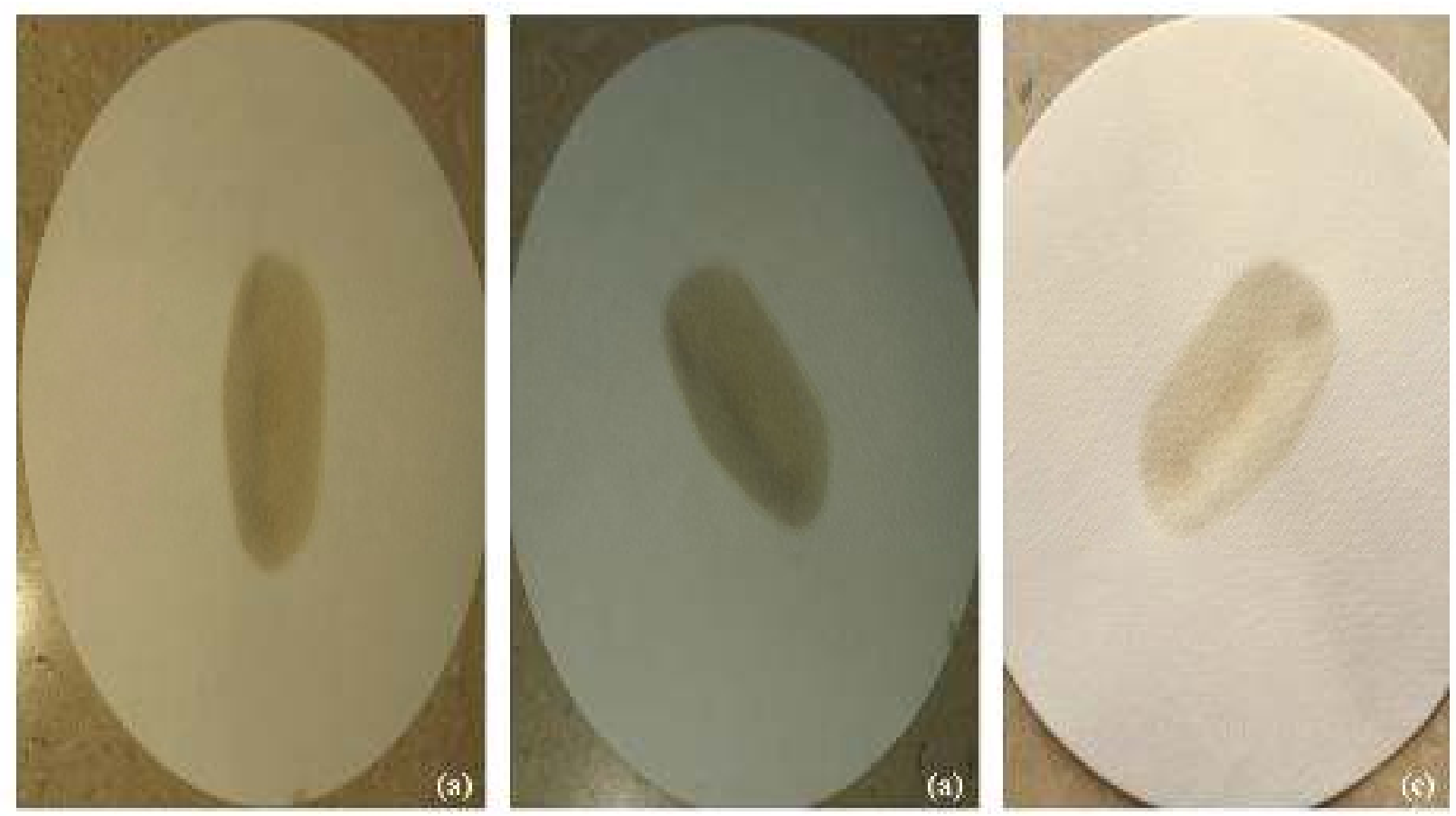

Figure No. 1 Oil and Resins Test. The transparent color is an indication of oil and resins (a) artichoke (b) lavender (c) alkanet. 

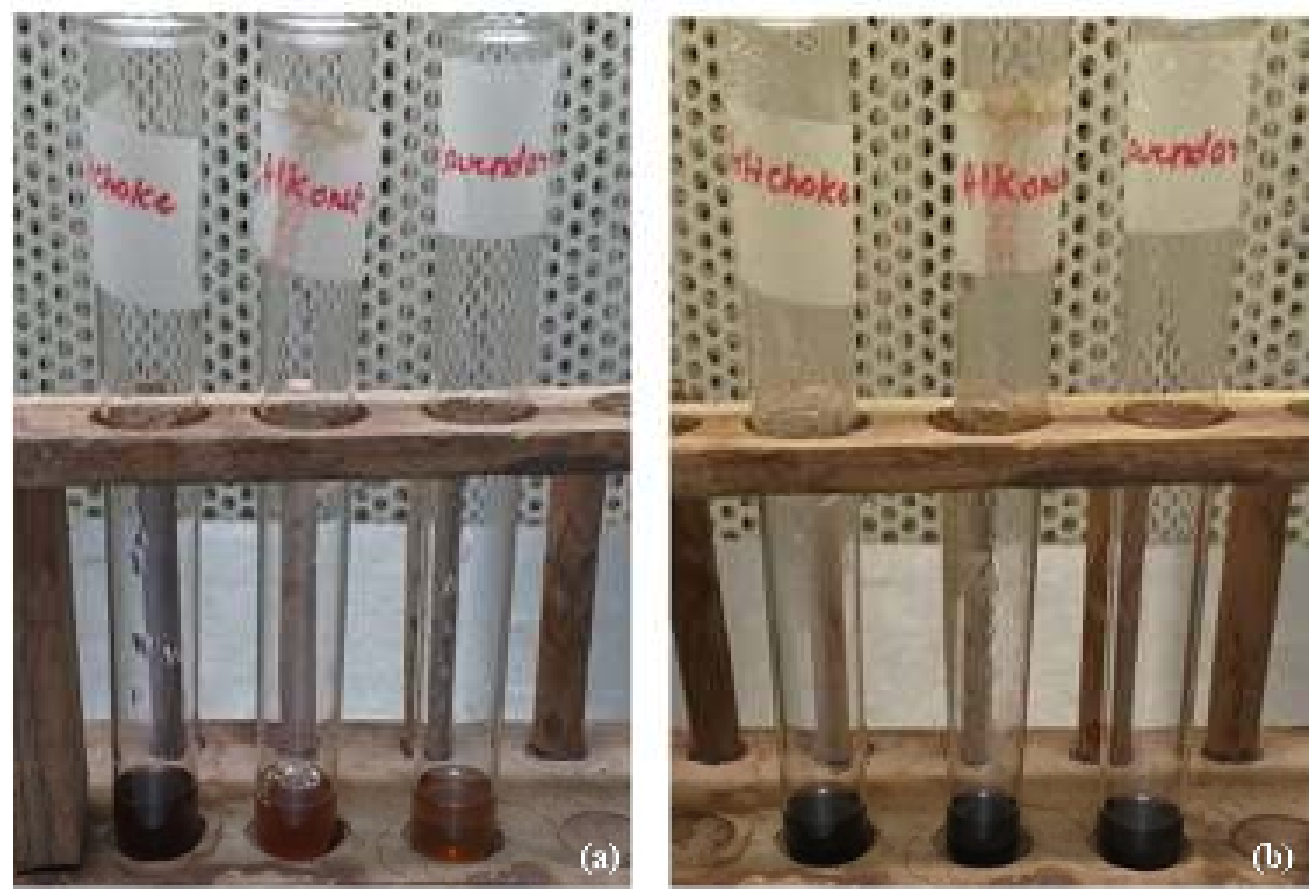

Figure No. 2. Ninhydrin test. (a) shows Ninhydrin test control for artichoke, lavender, alkanet. (b) showed dark blue color in respective plants which indicates presence of proteins and amino acids.

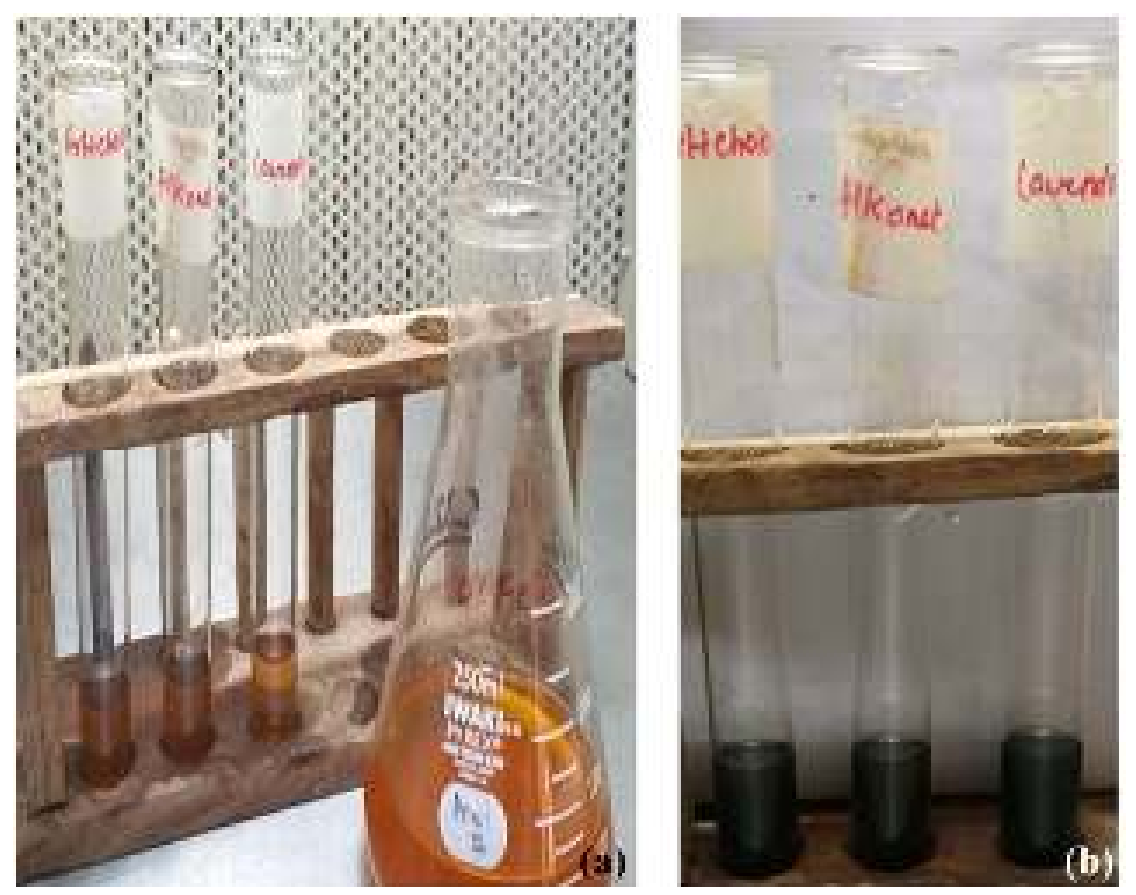

Figure No. 3. Presence of Phenols. (a) control for artichoke, lavender, alkanet. (b) Indicates the the extracts were positive for the presence of phenols in respective plants. 


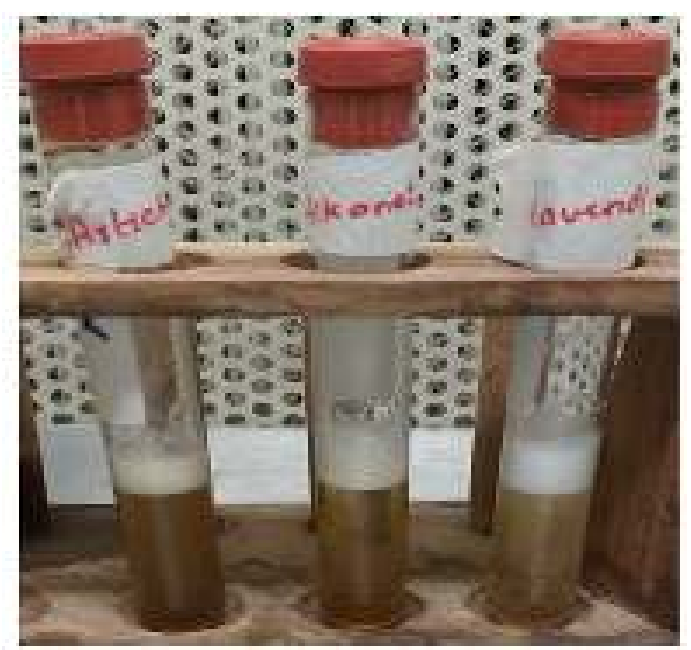

Figure No. 4. Presence of saponins. The test confirmed the presence of saponins in all extracts as indicated by foam in top layer.
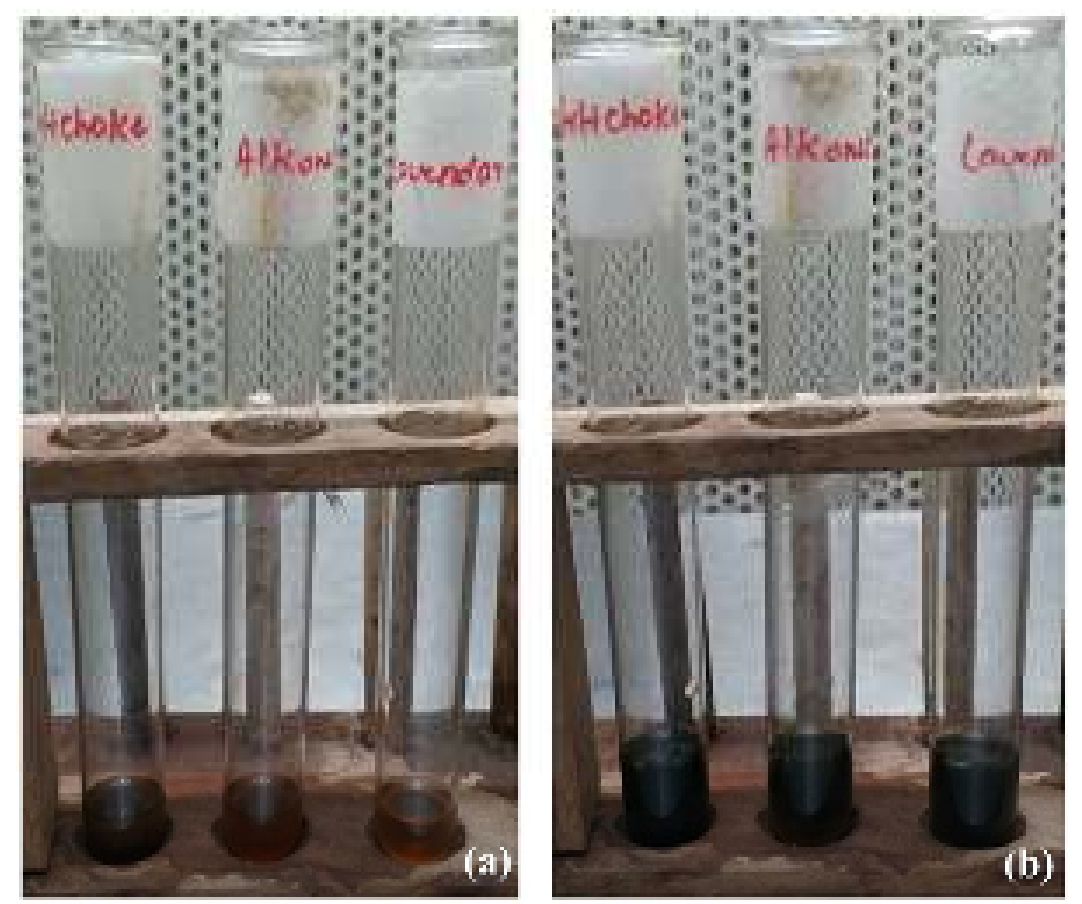

Figure No. 5. Presence of tannins. (a) controls for tannin tests. (b) The plant extracts (artichoke, lavender, alkanet) were positive for tannins as indicated by colour change. 

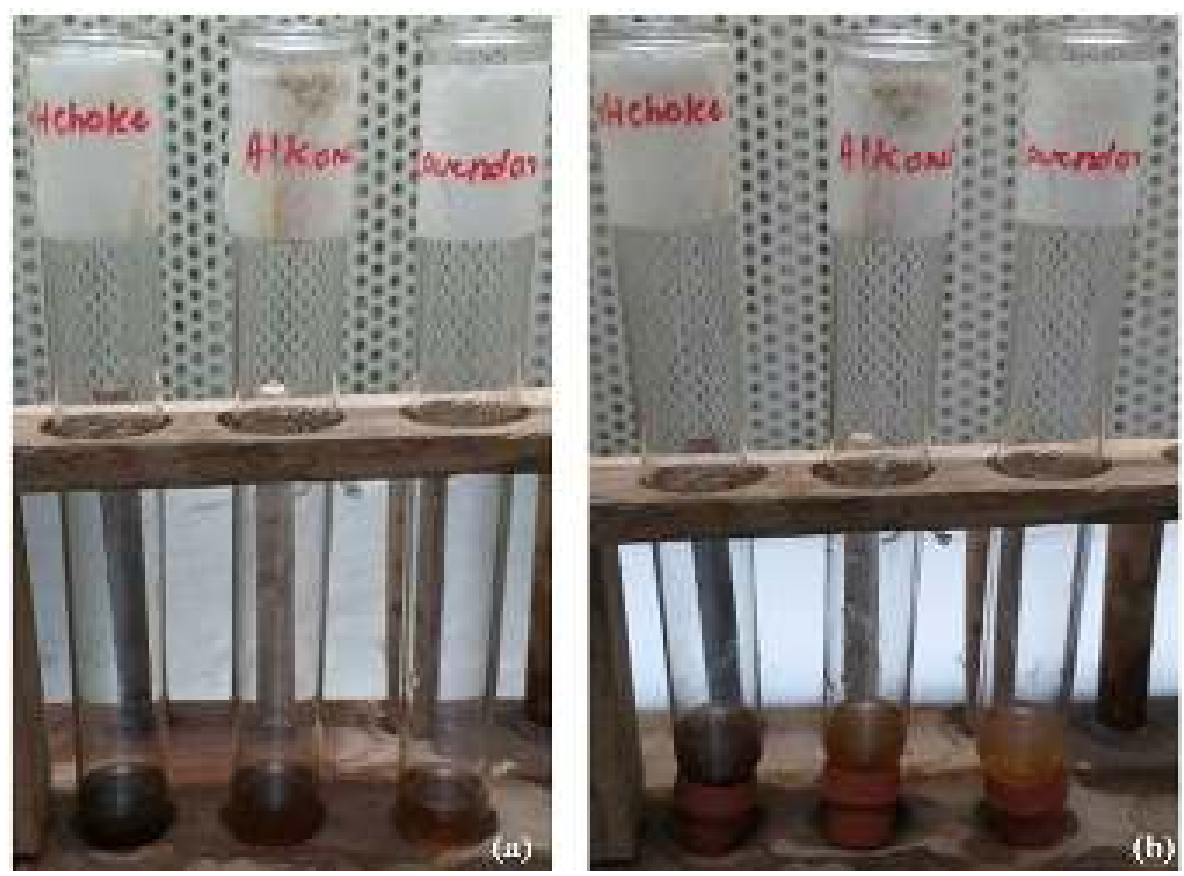

Figure No. 6. Presence of flavonoids. (a) Controls for artichoke, lavender, alkanet (b) the test confirmed presence of flavonoids in the respective extracts.
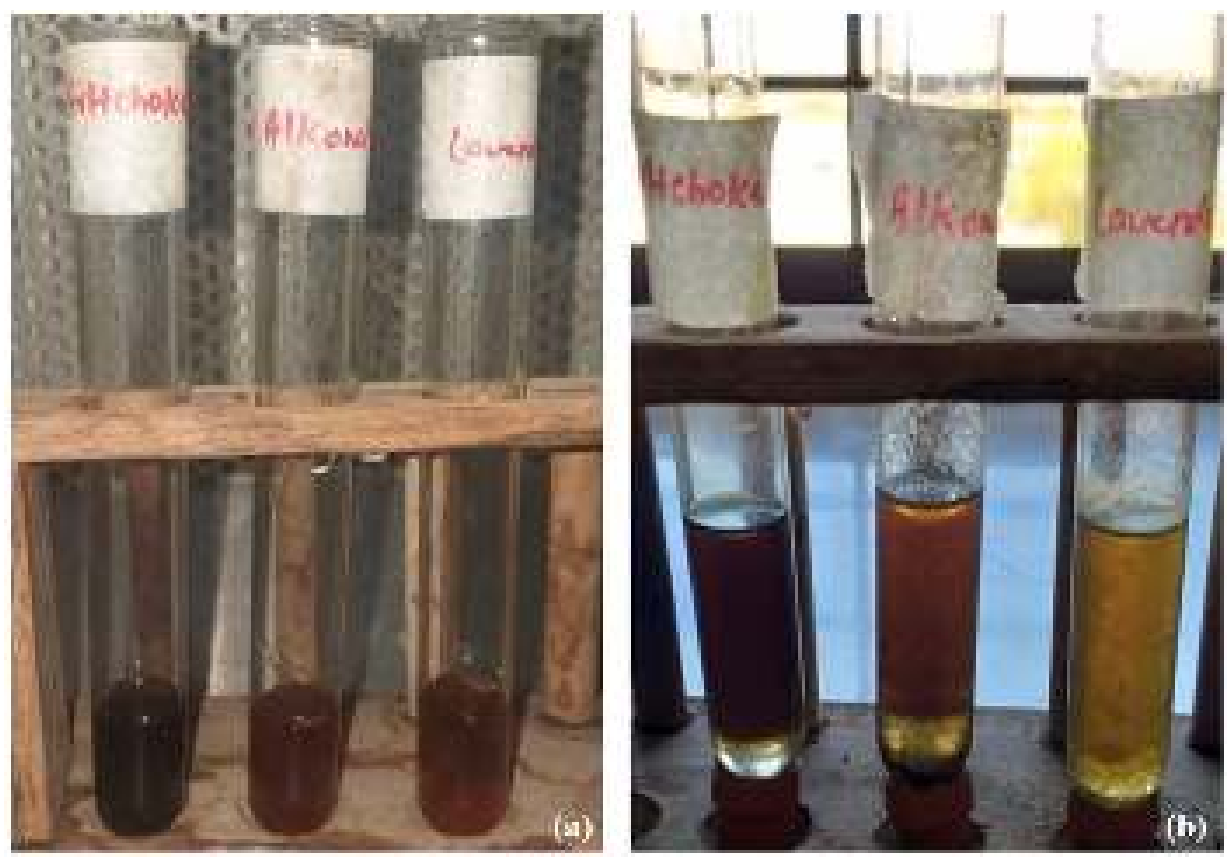

Figure No. 7. Presence of terpenoids. (a) controls for artichoke, lavender and alkanet extracts. (b) Salkowski's test confirmed presence of terpenoids in the respective extracts. 

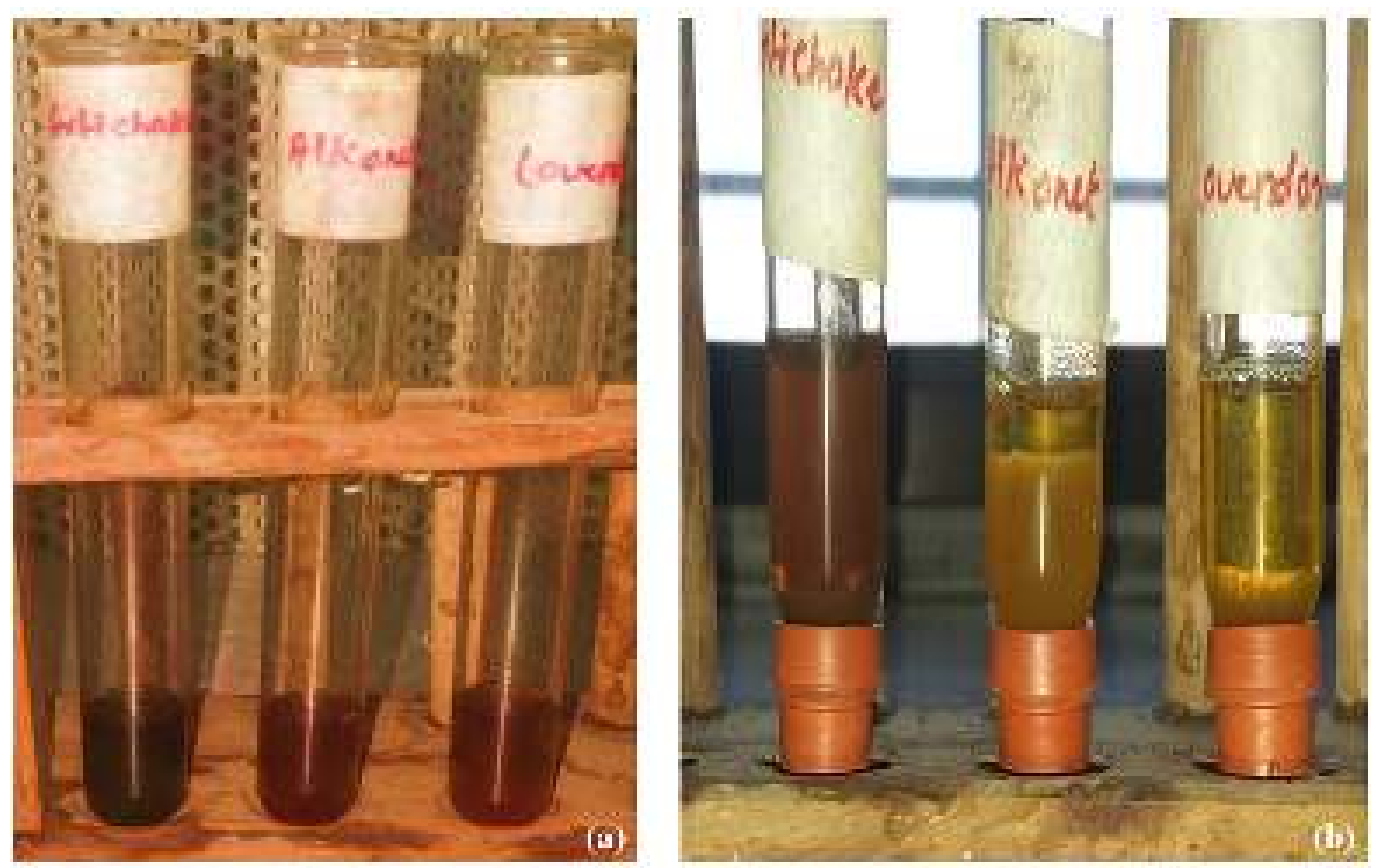

Figure No. 8. Presence of Alkaloids. (a) controls for artichoke, lavender, and alkanet extract (b) Hager's test confirmed the presence of Alkaloids in the respective extracts.
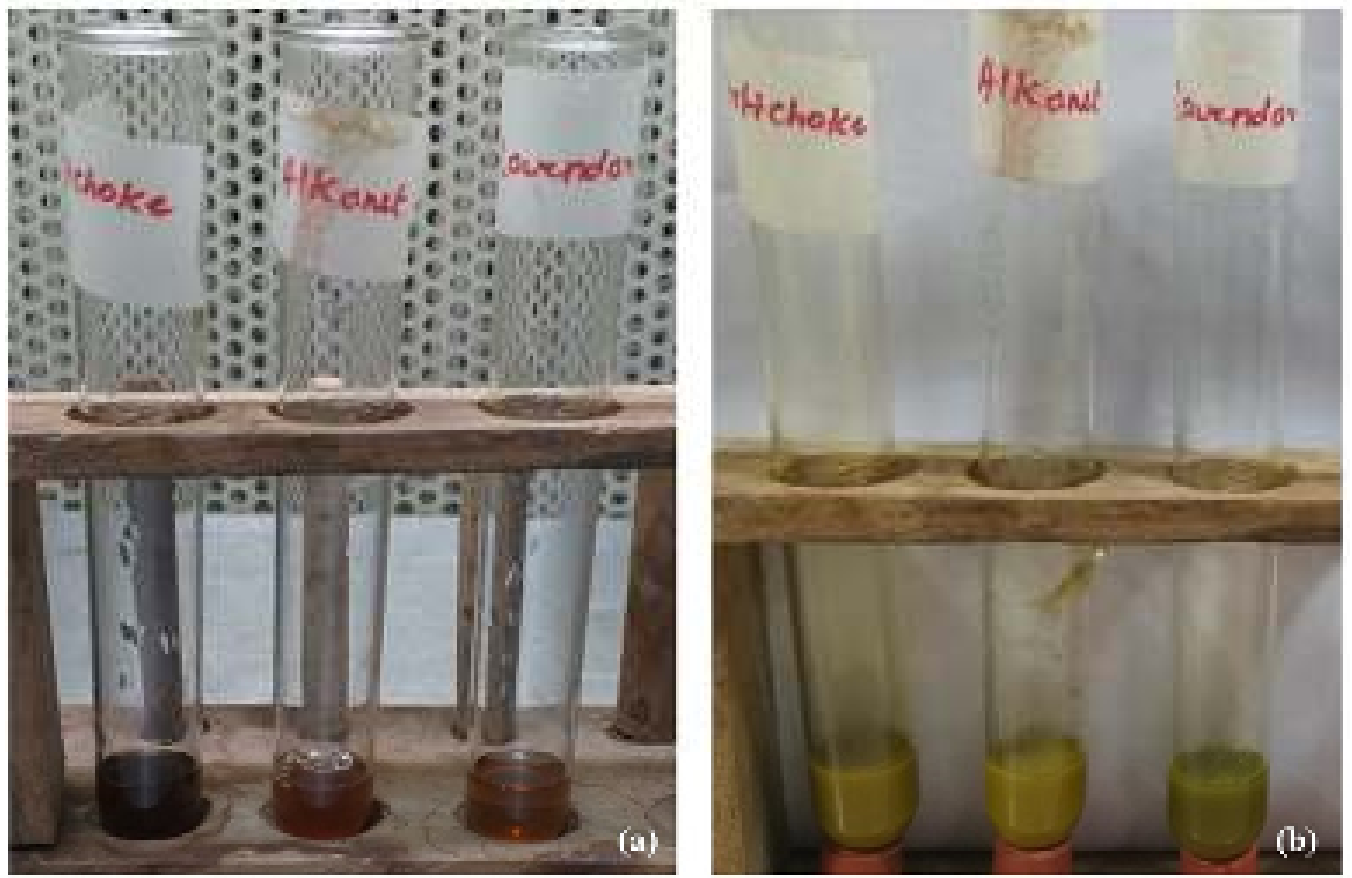

Figure No. 9. Presence of carbohydrates. (a) controls for artichoke, lavender, alkanet extracts. (b) Benedict's test confirms the presence of carbohydrates in the respective extracts.

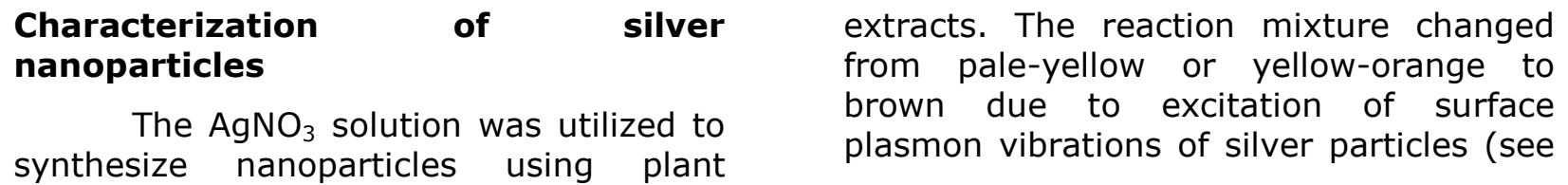


figure No. 10). This colour change reflects the successful synthesis of silver nanoparticles (Veerasamy et al., 2011). Plant extract comprises of reducing agents such as flavanones, phenolics, and terpenoids known to reduce silver ions to silver nanoparticles. A similar study conducted on rosemary mediated synthesis of silver nanoparticles showed chemical components such as: caffeic acids, phenolic compounds, hydrocinnamic acids and rosemarinic acid involve in reducing $\mathrm{Ag}+$ to $\mathrm{Ag}$ particle due to high scavenging ability to suppress the formation of free radicals (Qayyum et al., 2020).
UV-Vis spectrophotometer was used to characterize silver nanoparticles. The reduction of silver ions to $\mathrm{Ag}^{\circ}$ particle was confirmed by a sharp peak around $400 \mathrm{~nm}$ for respective solutions (see figure No. 11). A similar study by Erdogan et al (2019) demonstrated change in colour of reaction due to the excitation of surface plasmon on metal (silver) nanoparticles. Whereas brown-orange colour of the silver nanoparticle colloidal solution was apparent and confirmed AgNP synthesis. This characteristic peak around 400-450 $\mathrm{nm}$ is specific for AgNPs confirming the synthesis of AgNPs owing to its range of surface plasmon resonance (SPR) (Saji et al., 2010).

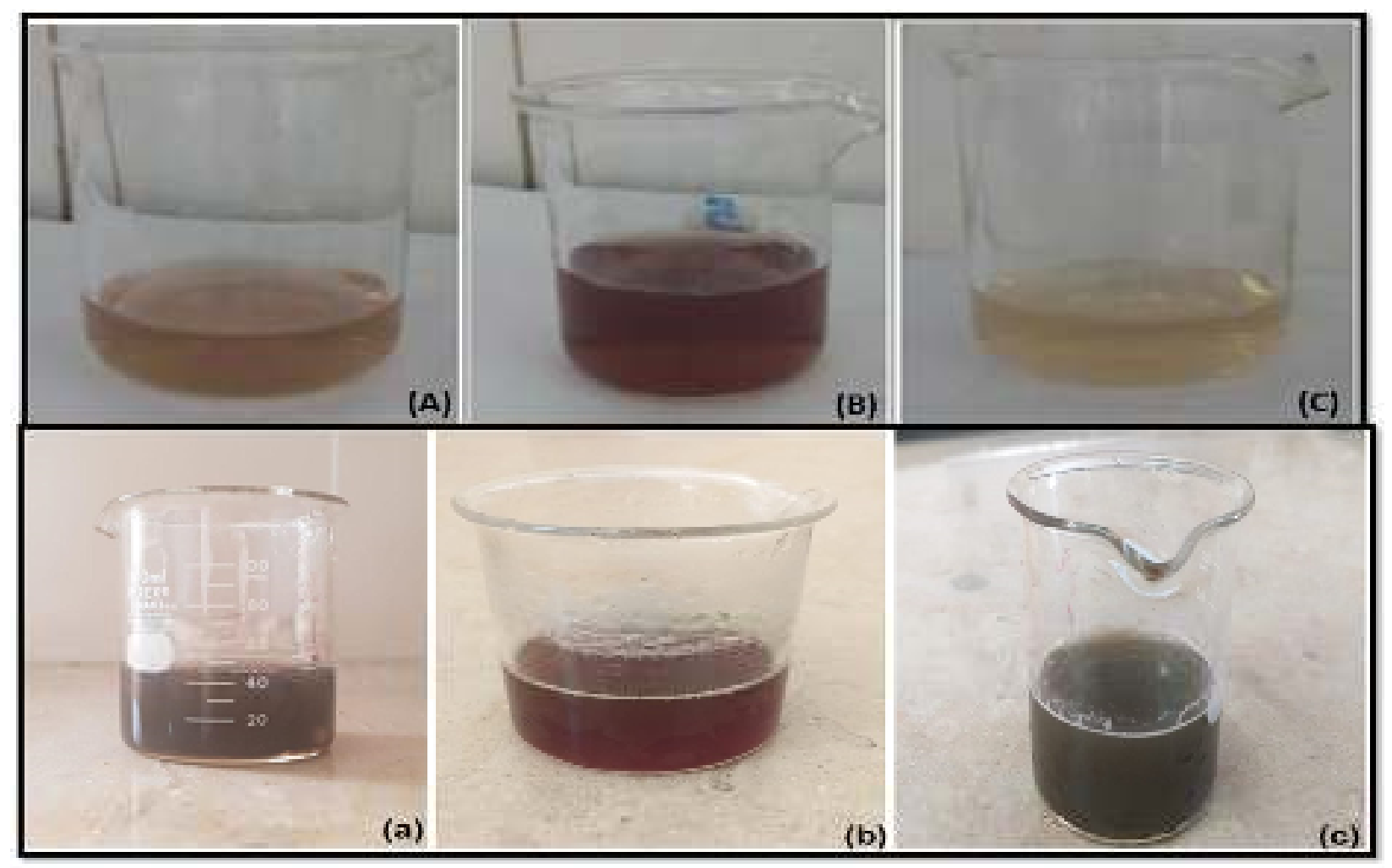

Figure. No. 10. Visual characterization of silver nanoparticles using plant extracts. Observing color change of (A) Artichoke extract to (a) Artichoke mediated silver nanoparticle, (B) Alkanet leaves extract mediated synthesis of (b) biogenic alkanet silver nanoparticle as observed by brown color of final solution (C) lavender extract converts from light yellow extract to dark brown in color of (c) solution which confirms synthesis of silver nanoparticle. 


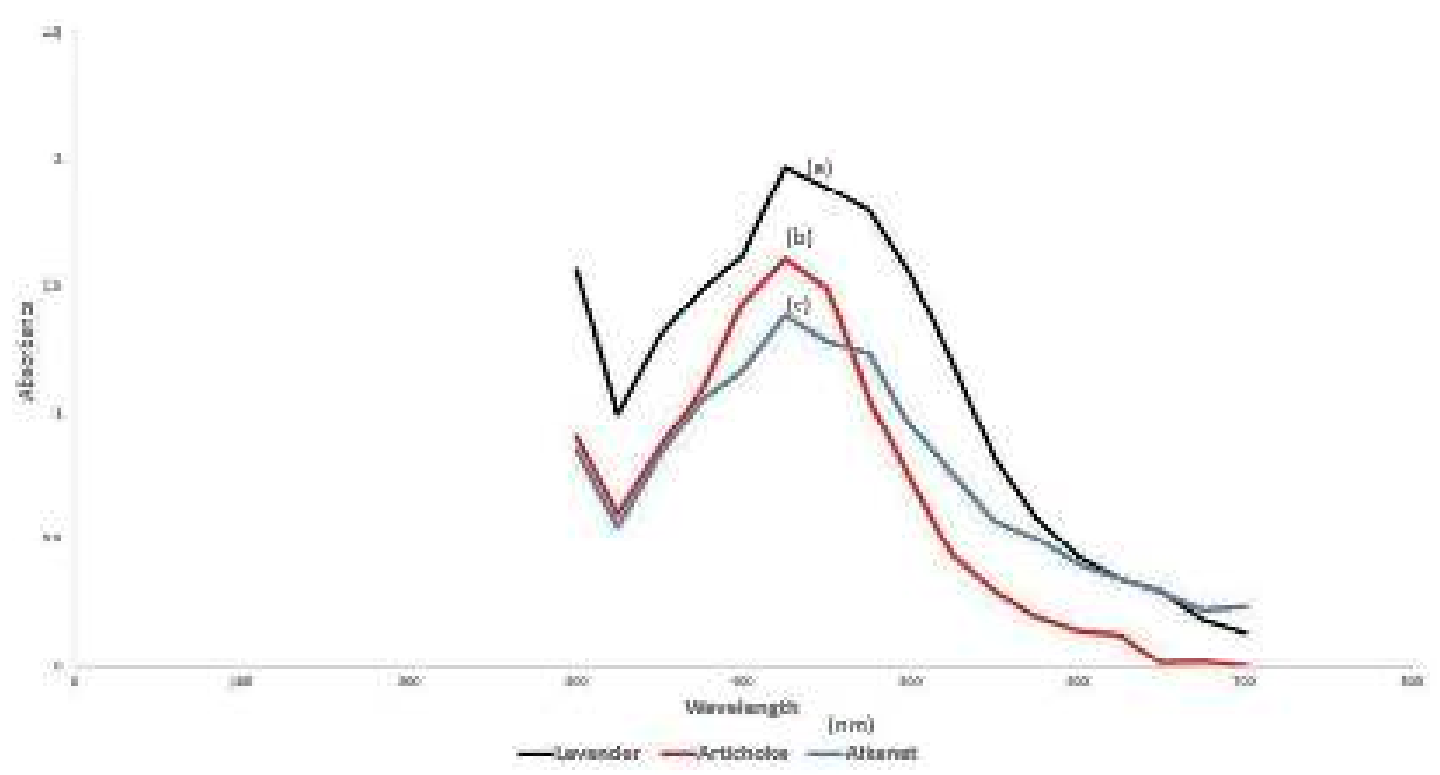

Figure. No. 11. Characterization of Silver nanoparticles using UV-VIS spectrophotometer. The colloidal solution of silver nanoparticles for respective solution was measured between $300 \mathrm{~nm}$ to $600 \mathrm{~nm}$. The spectrum for (a) Lavender mediated silver nanoparticles showed peak between 320 to $370 \mathrm{~nm}$, (b) Artichoke mediated silver nanoparticles showed peak between 320 to $350 \mathrm{~nm}$ and (c) Alkanet mediated silver nanoparticles showed peak between 300-350nm. 


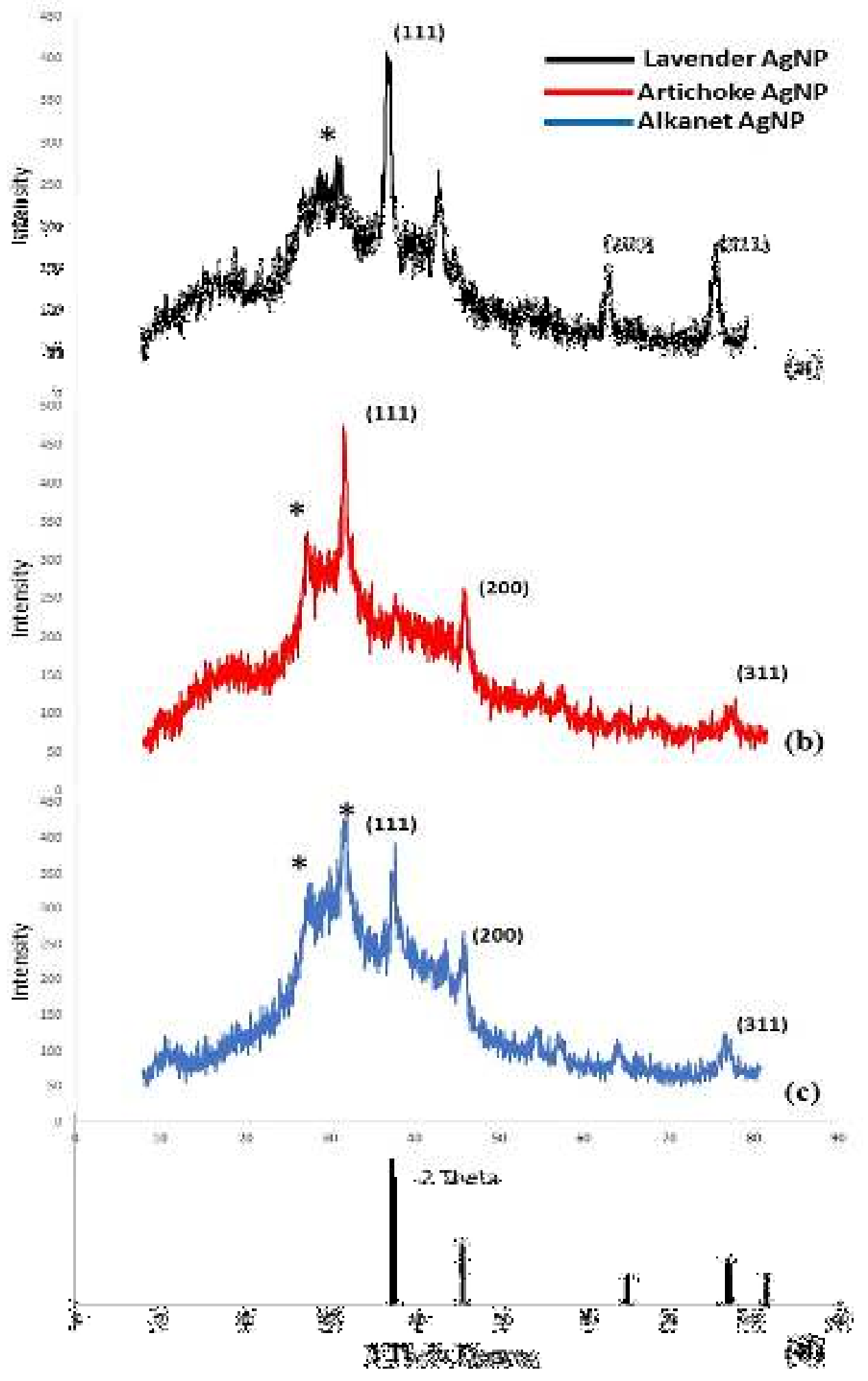

Figure. No. 12. Characterization of Silver nanoparticles using X-ray Diffraction. The XRD pattern confirms powdered particles as silver nanoparticles synthesized from the respective plant sources i.e. (a) Lavender (b) Artichoke, (c) Alkanet. The sharp fine peaks illustrate the presence of silver nanoparticles as compared and matched with (JCPDS file No. 04-0783) of silver nanoparticles. 
The crystal size and nature of biogenic nanoparticles was identified using XRD in the range $30-70^{\circ}$ at $2 \theta$ angles. The synthesized nanoparticles were confirmed with standard silver nanoparticles (JCPDS file No. 04-0783) The spectrum gives sharp peaks which confirmed silver nanoparticles synthesis via three different plant sources. XRD patterns of three biogenic silver nanoparticles showed distinct peaks at around $38^{\circ}, 44^{\circ}$ and $77^{\circ}$ corresponding to peak positions at 111,200 , and 311 according to Bragg reflections, respectively. However, unidentified peaks marked as $(*)$ represented the impurities in the sample of plant extract (Figure 12). These peaks indicate the presence of plant metabolite residues on the surface of AgNPs that were used as capping agents on AgNPs, also supported by Pirtarighat et al. (2019) results. Other minor peaks on

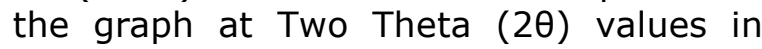
AgNPs pattern can be recognized as the residues of the organic content present in the respective plant extract (Lanje et al., 2010). The average size for silver nanoparticles was obtained using FullWidth Half-Maximum (FWHM) using Debye-Scherer's formula for lavender, Artichoke and Alkanet mediated nanoparticles was $35 \mathrm{~nm}, 42 \mathrm{~nm}$ and 54 $\mathrm{nm}$ respectively. This result is in accordance with XRD analysis of Oves et al. (2018). The $\mathrm{AgNO}_{3}$ dissociates in water and forms cation ion and anions. These cations further forms hydroxyl complexes and takes up various plant metabolites as capping agent to form Ag nanoparticles. Here plant extracts serves as reducing agent and donate its electron to the Agion to complete the formation of $\mathrm{Ag}$ particles. Moreover, high level of plant extracts as capping and stabilizing agent ensures uniform capping of nanoparticles and prevent aggregation of nanoparticles (Makarov et al., 2014)

\section{Antibacterial activity}

Silver nanoparticles synthesized using three different plant sources were tested against gram-positive ( $S$. aureus) and gram-negative (E.coli) bacteria. These strains causes life-threatening diseases in humans such as pneumonia, urinary tract infections (UTI), and gastrointestinal infections (GIT). Artichoke mediated synthesis of silver nanoparticles showed clear zones of inhibition for $E$. coli $(1.25 \mathrm{~cm} \pm 0.20)$ and $S$. aureus $(1.45 \mathrm{~cm} \pm$ $0.10)$. Our results indicated that the effect of artichoke mediated AgNPs was greater on $S$. aureus as compared to $E$. coli (figure 13). As S. aureus is gram-positive and its cell wall is composed of thick peptidoglycan layer which makes them vulnerable to AgNPs. AgNPs has bactericidal and bacteriostatic effect owing to its larger surface area to volume ratio. These nanoparticles damages the cytoplasmic membrane and increases cell permeability that leaks cellular contents that leads to cell death. Bacteriostatic activity of AgNP involves the interaction of functional groups present on surface nanoparticles with bacterial membrane proteins, phospholipids, lipoproteins, and lipo-teichoic acids and reduces its colonization and surface adherence (Pereira et al., 2014). 


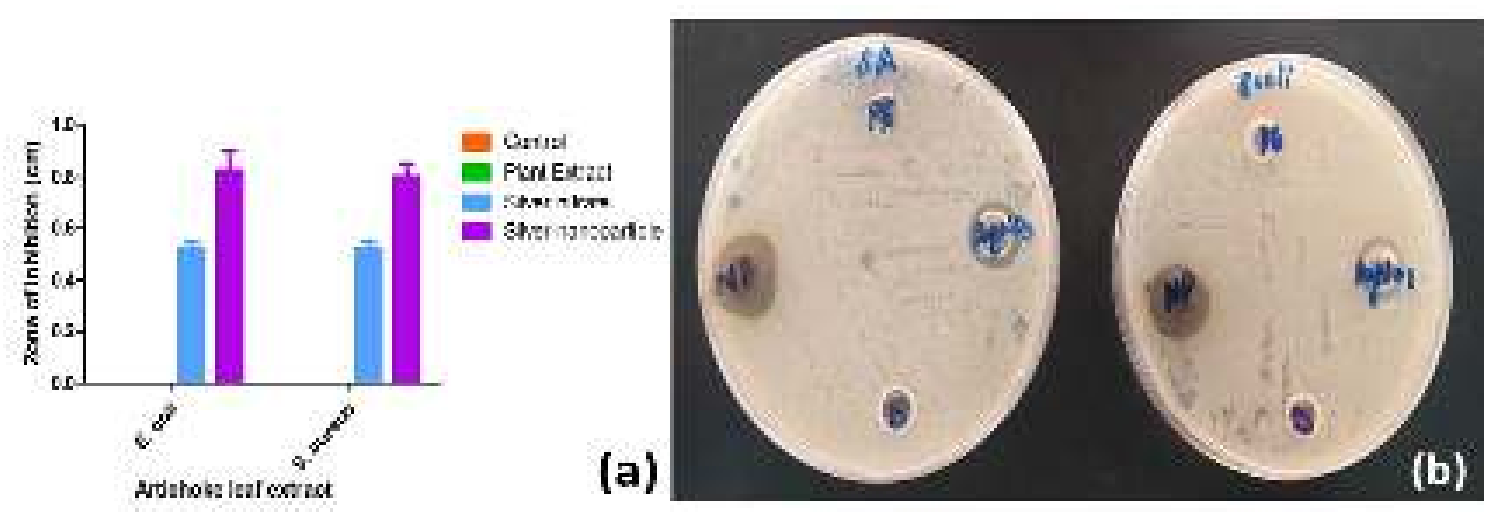

Figure no. 13. Antibacterial activity of Artichokes mediated silver nanoparticles. (a) Graphical representation showed significant effect of Artichoke mediated silver nanoparticle as compared to silver nitrate on E. coli and S. aureus. (b) illustration of AgNPs against $E$. coli and $S$. aureus as compared to its respective negative (water and Plant extract) and Positive control (Silver nitrate).
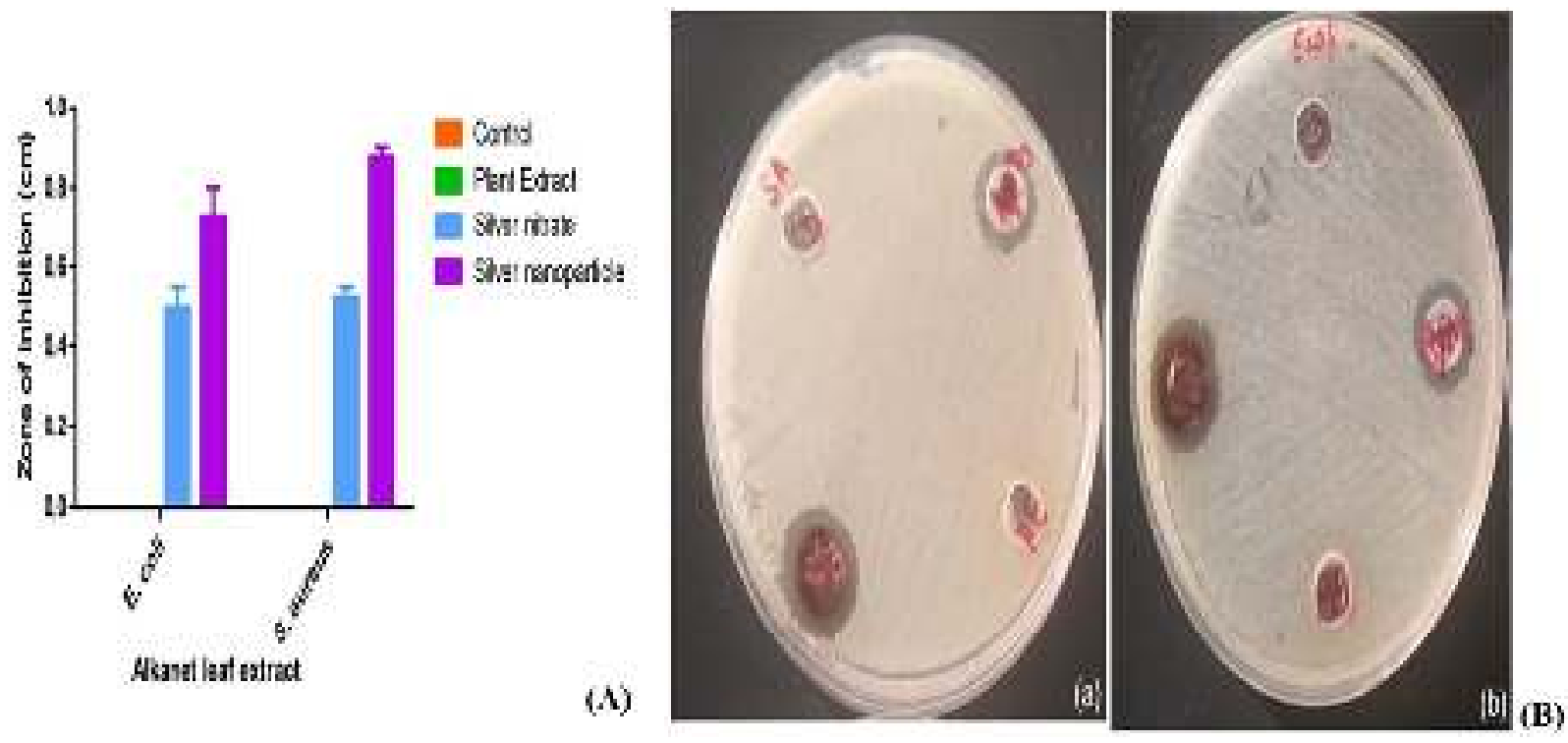

Figure no. 14. Antibacterial Activity of silver nanoparticles mediated by Alkanet. (A) Graphical representation showed significant effect of Alkanet mediated silver nanoparticle as compared to silver nitrate on E. coli and S. aureus. (B) illustration of AgNPs against (a) S. aureus (b) E. coli as compared to its controls. 


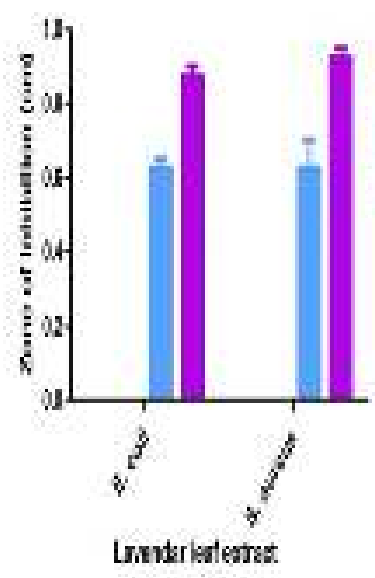

Figure no.15. Antibacterial Activity of lavender mediated silver nanoparticle. Graphical representation showed significant effect of Lavender mediated silver nanoparticle as compared to silver nitrate on E. coli and S. aureus. (B) illustration of AgNPs against (a) S. aureus (b) E. coli as compared to its controls.
Lavender mediated silver nanoparticles affected $E$. coli $(1.3 \mathrm{~cm} \pm$ $0.10)$ significantly than $S$. aureus $(1.25 \mathrm{~cm}$ $\pm 0.20)$ as compared to its respective controls (see figure No. 15). The impact of Alkanet mediated silver nanoparticles was lower as compared to Artichoke and Lavender mediated silver nanoparticles. However, the alkanet based silver nanoparticles showed a significant effect on $E$. coli $(1.2 \mathrm{~cm} \pm 0.0)$ and $S$. aureus $(1.25 \mathrm{~cm} \pm 0.10)$ as compared to its respective control (see figure No. 14). Khan et al. (2015) describe bacteriostatic activity of Alkanna tinctoria extract that inhibits cell division of microbes. Hui et al. (2010) identified the antimicrobial activity of Lavandula angustifolia extract involved in disrupting membrane permeability by creating pores that leak its cellular contents.

\section{Antifungal activity:}

We identified the antifungal activity of biogenic nanoparticles from three different plant sources against Aspergillus niger and Aspergillus flavus. These fungal strains are known for causing aspergillosis and have a saprophytic (decaying) mode of nutrition. Our results showed a contrasting activity of biogenic silver nanoparticles as compared to its antibacterial effect. Artichoke mediated silver nanoparticles showed a significant impact on plant-pathogen as compared to other biogenic nanoparticles. This effect was followed by Alkanet mediated silver nanoparticles, whereas lavender mediated silver nanoparticles were least effective. Artichoke nanoparticles showed a greater zone of inhibition for both Aspergillus niger $(1.2 \mathrm{~cm} \pm 0.0)$ and Aspergillus flavus $(1.0 \mathrm{~cm} \pm 0.0)$ as compared to their respective controls (Figure no. 16). Antifungal activity of silver nanoparticles produced from Alkanet showed a prominent impact on Aspergillus flavus $(0.9 \mathrm{~cm} \pm 0.0)$ than Aspergillus niger $(1.8 \mathrm{~cm} \pm 0.0)$ (Figure no. 17). Lavender mediated silver nanoparticles showed lower activity against fungal strains as compared to its antibacterial activity. Moreover, biogenic silver nanoparticles from lavender showed prominent antifungal activity against Aspergillus flavus $(0.8 \mathrm{~cm} \pm 0.0)$ followed by silver nitrate effect on Aspergillus niger $(0.6 \mathrm{~cm}$ \pm 0.0 ) (Figure no. 8). A study conducted to test antifungal activity of Cannabis sativa against Aspergillus flavus confirmed high activity of n-butanol extract (Khan and javaid, 2020). Agriculture contributes to economic development of countries. There are numerous types of plant 
pathogens, whereas fungi are the most common plant pathogens, and prompts crop losses. Thus, the export of highquality fruits is reduced due to increased fungal infections of plants. A lot of natural and artificial methods are used to overcome the agricultural losses. Fungicides are commonly used to control diseases yet its residues runoff into environment posing threat for humans and animals. Therefore, an alternative use of nanoparticle instead of fungicides can open ways to control fungal infections in plants, increase crop productivity, and protect plants without harming the environment (Jo et al., 2009). Silver is the most reliable metal widely to inhibit the growth of microorganisms and is also used as a disinfectant against many pathogens (Kim et al., 2004).
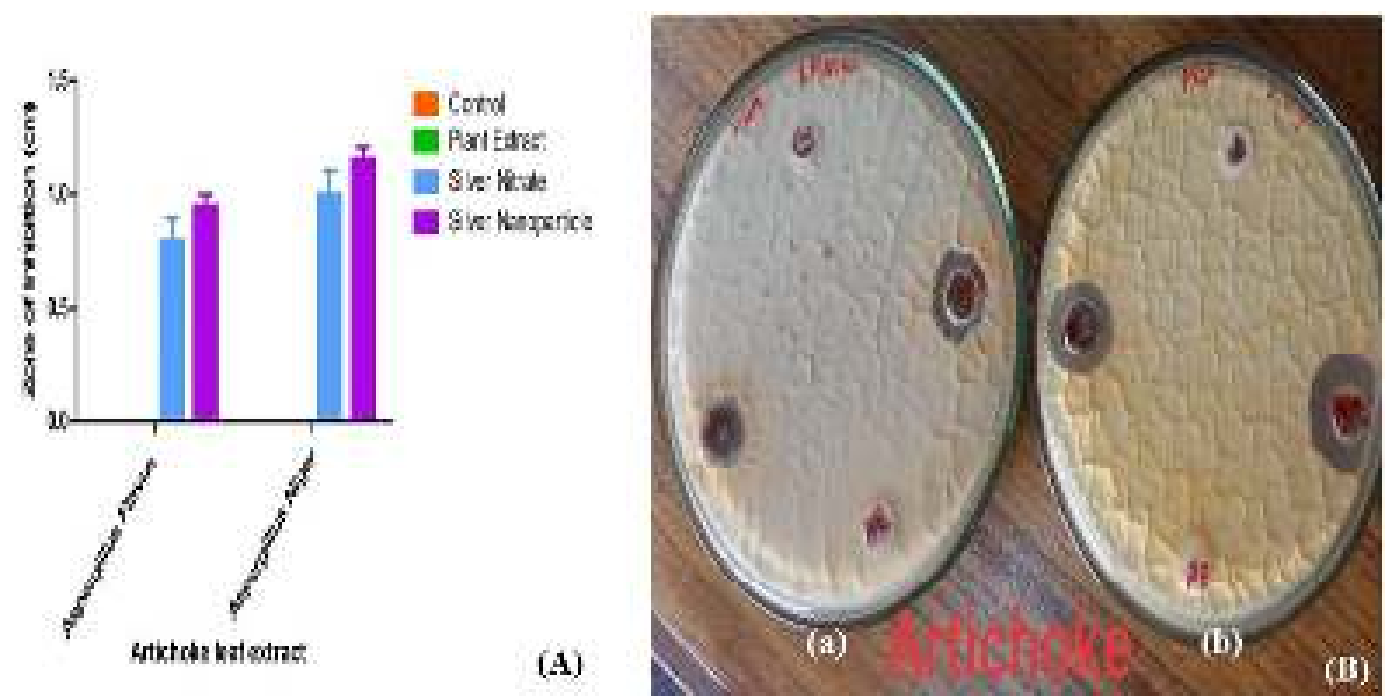

Figure no. 16. Antifungal activity of Artichoke mediated silver nanoparticles. Graphical representation showed significant effect of Artichoke mediated silver nanoparticle as compared to silver nitrate on Aspergilus flavus and Aspergilus niger. (B) illustration of AgNPs showed prominent antifungal activity against (a) Aspergilus flavus and (b) Aspergilus niger as compared to its controls.

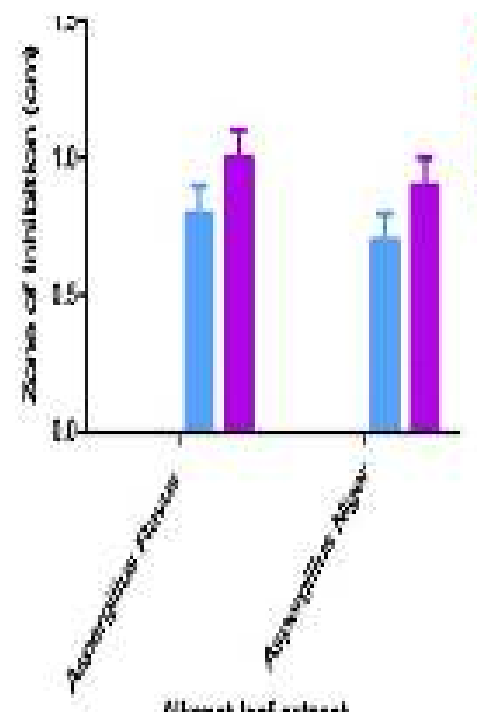

Chanet laf eatract

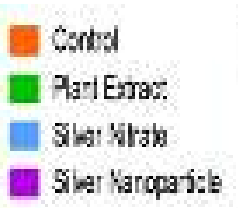

(A)

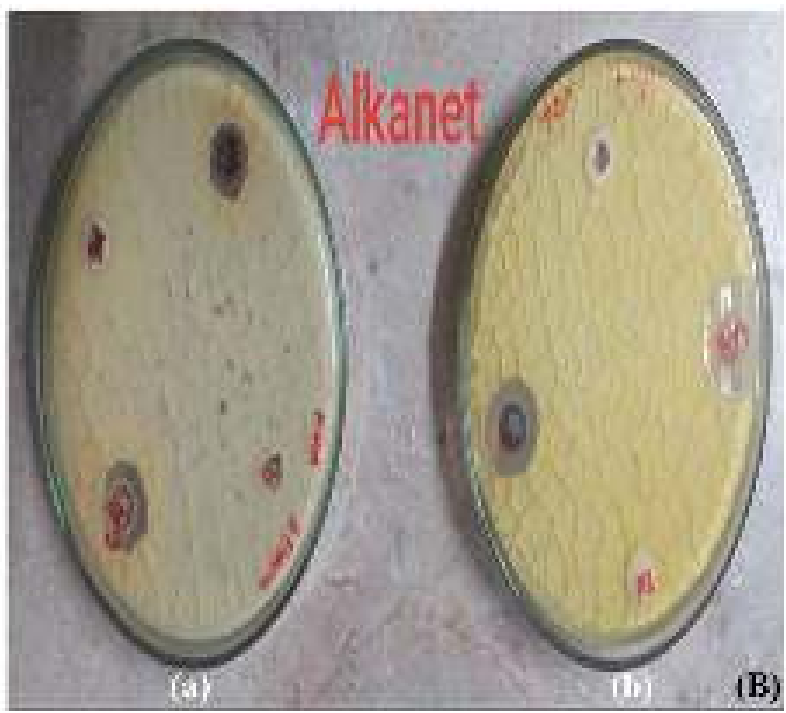

Figure no. 17. Antifungal activity of Alkanet mediated activity of nanoparticle. Graphical representation showed significant effect of Alkanet mediated silver nanoparticle as 
compared to silver nitrate on Aspergilus flavus and Aspergilus niger. (B) illustration of AgNPs showed promiinent antifungal activity against (b) Aspergilus niger than (a) Aspergilus flavus as compared to its controls.

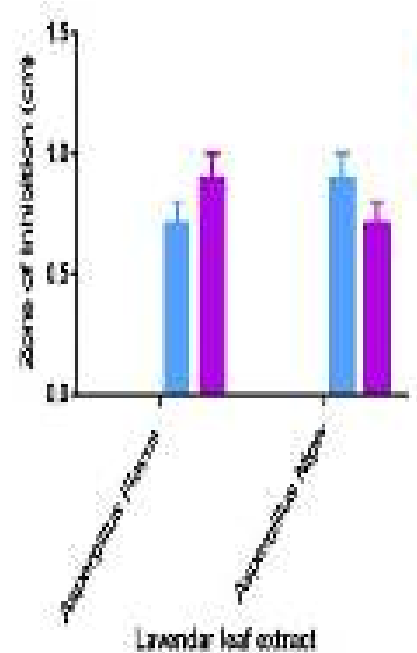

Lsผndr loof edral

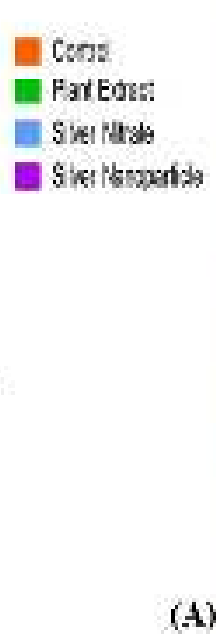

(A)

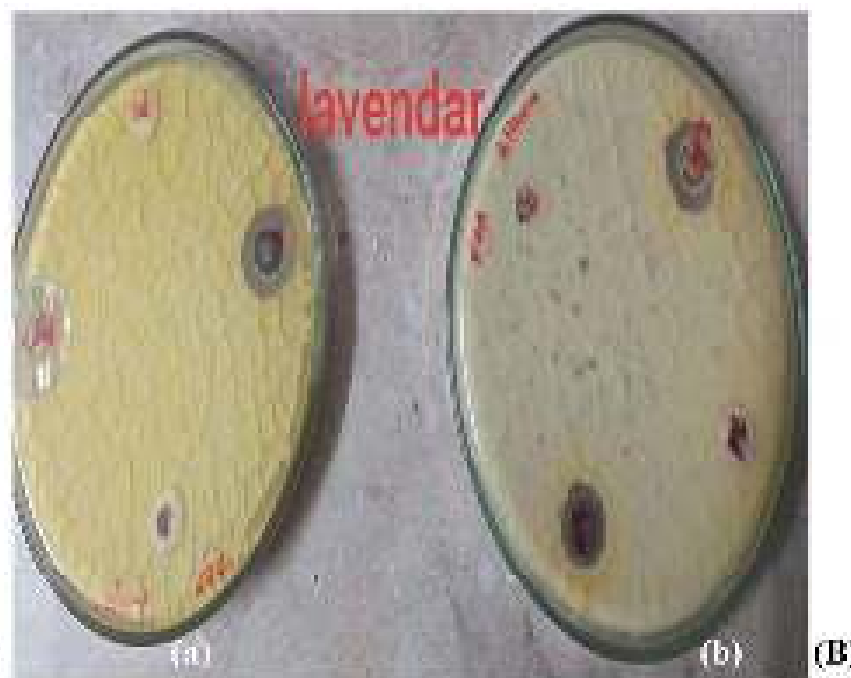

Figure no. 18. Antifungal activity of Lavender mediated silver nanoparticle. Graphical representation showed significant effect of lavender mediated silver nanoparticle as compared to $\mathrm{AgNO}_{3}$ on Aspergilus flavus and Aspergilus niger. (B) illustration of AgNPs showed prominent antifungal activity against (a) Aspergilus flavus and (b) Aspergilus niger as compared to its controls.

Artichoke consists of many biomolecules such as cynarin and chlorogenic acid which exhibit great antimicrobial activities against various microorganisms (Zhu et al., 2004). Alkanet has pharmaceutical important bioactive components such as Hydroxynaphthoquinones (HNQ) which possess properties like, antimicrobial activities, anti-inflammatory and wound healing etc (Terzieva et al., 2019). Lavender also contains Linalool, linalyl and lavandulyl acetate which exhibits antibacterial and antifungal activities (Prusinowska et al., 2016). Kim et al. (2012) studied the activity of silver nanoparticles against many phytopathogenic fungi such as Alternaria alternata, Alternaria brassicicola, Alternaria solani, Botrytis cinereal, Cladosporium cucumerinum, Corynespora cassiicola, Cylindrocarpon destructans, Didymella bryoniae, Fusarium oxysporum f. sp. Cucumerinum, F. oxysporum f. sp. Lycopersici, F. oxysporum, Fusarium solani, Glomerella cingulate, Monosporascus cannonballus, Pythium aphanidermatum, Pythium spinosum, Stemphylium lycopersici and found significant antifungal activity against these respective fungal species.

Conclusion: The current study is a comparative approach to identify the efficacy of three different biogenic silver nanoparticles synthesized from Cynara scolymus (Artichoke), Alkanna Tinctoria (Alkanet), Lavandula angustifolia (lavender). The phytoconstituents in plant extracts were analysed qualitatively. The silver nanoparticles were characterized visually, via UV-Vis spectrophotometer and XRD. The synthesized nanoparticles showed the size of $35 \mathrm{~nm}, 42 \mathrm{~nm}$, and $54 \mathrm{~nm}$ for Lavender, Artichoke, and Alkanet respectively. Among three nanoparticles, lavender nanoparticles showed significant antibacterial activity due to its smallest size as compared to other nanoparticles. In contrast, artichoke showed greater antifungal activity against $A$. niger and $A$. flavus than two biogenic nanoparticles, whereas lavender 
nanoparticles showed the least effect on fungal strains. Biological synthesis of nanoparticles is an inexpensive, non-toxic, and eco-friendly procedure. Synthesis of nanoparticles using green sources (plants) are now used widely in many biomedical applications as well as in other fields also, as the plants mediated AgNPs are very effective, stable, and precise.

\section{Acknowledgments}

We acknowledge the cooperation of Dr. Abdul Hanan Director Baluchistan

\section{REFERENCES}

Abdel-Aziz, M.S., M.S. Shaheen, A.A. ElNekeety, M.A. Abdel-Wahhab. 2014. Antioxidant and antibacterial activity of silver nanoparticles biosynthesized using Chenopodium murale leaf extract. J. Saudi. Chem. Soc., 18(4): 356-363.

Ahmed, S., M. Ahmad, B.L. Swami, S. Ikram. 2016. A review on plants extract mediated synthesis of silver nanoparticles for antimicrobial applications: a green expertise. $J$. Adv. Res., 7(1): 17-28.

Banu, K.S., L Cathrine. 2015. General techniques involved in phytochemical analysis. Int. J. Adv. Res. Chem. Sci., 2(4): 25-32.

Erdogan, O., Abbak, M., Demirbolat, G. M., Birtekocak, F., Aksel, M., Pasa, S., \& Cevik, O. 2019. Green synthesis of silver nanoparticles via Cynara scolymus leaf extracts: The characterization, anticancer potential with photodynamic therapy in MCF7 cells. PloS one., 14(6): e0216496.

Gajbhiye, M., J. Kesharwani, A. Ingle, A. Gade, M. Rai. 2009. Fungus-mediated synthesis of silver nanoparticles and their activity against pathogenic fungi in combination with fluconazole. Nanomed Nanotechnol., 5(4): 382386.

Hui, L., L. He, L. Huan, L. XiaoLan, Z. AiGuo. 2010. Chemical composition of
Agricultural Research Centre (BARC) for providing us with Alkanet, Artichoke and Lavender plants to conduct this research. We are thankful to Agriculture College Quetta for providing us Plant fungal strains. We also acknowledge Petroleum and Gas department BUITEMS for conducting XRD of synthesized nanoparticles.

\section{Conflict of interest:}

The authors have no conflict of interest

lavender essential oil and its antioxidant activity and inhibition against rhinitis-related bacteria. Afr. J. Microbiol. Res., 4(4): 309-313.

Iravani. S., H. Korbekandi, S. V. Mirmohammadi, B. Zolfaghari. 2014. Synthesis of silver nanoparticles: chemical, physical and biological methods. Res. Pharm Sci., 9(6): 385.

Jain. D., H.K. Daima, S. Kachhwaha, S.L. Kothari. 2009. Synthesis of plantmediated silver nanoparticles using papaya fruit extract and evaluation of their antimicrobial activities. Dig. J. Nanomater. Bios., 4(3): 557-563.

Jo. Y.K., B.H. Kim, G. Jung. 2009. Antifungal activity of silver ions and nanoparticles on phytopathogenic fungi. Plant Dis., 93:1037-43.

Khan. T., M.A. Khan, A. Nadhman. 2015. Synthesis in plants and plant extracts of silver nanoparticles with potent antimicrobial properties: current status and future prospects. Appl. Microbiol. Biot., 99(23): 9923-9934.

Khan, I. H., \& Javaid, A. 2020. Antifungal Activity of Leaf Extract of Cannabis sativa Against Aspergillus flavipes. Pak. J. Weed Sci. Res, 26(4), 447-453.

Kim. J.H. 2004. Nano silver chemotherapeutic agents and its applications. News Inf. Chem. Eng., 22: $655-60$ 
Kim. S.W., J.H. Jung, K. Lamsal, Y.S. Kim, J.S. Min, Y.S. Lee. 2012. Antifungal effects of silver nanoparticles (AgNPs) against various plant pathogenic fungi. Mycobiology., 40(1): 53-58.

Lanje, A. S., S. J. Sharma. And R. B. Pode. 2010. Synthesis of silver nanoparticles: a safer alternative to conventional antimicrobial and antibacterial agents. J. Chem. Pharm. Res, 2(3), 478-483.

Makarov V.V., Love A.J., Sinitsyna O.V., Makarova S.S., Yaminsky I.V., Taliansky M.E., Kalinina N.O. 2014. "Green" nanotechnologies: Synthesis of metal nanoparticles dsing plants. Acta Nat, 6, 35-44

Oves. M., M. Aslam, M.A. Rauf, S. Qayyum, H.A Qari, M.S. Khan, M.Z. Alam, S. Tabrez, A. Pugazhendhi, M. Ismail. 2018. Antimicrobial and anticancer activities of silver nanoparticles synthesized from the root hair extract of Phoenix dactylifera. Mat. Sci. Eng. C-Mater., 89: 429-443.

Pereira. L., N. Dias, J. Carvalho, S. Fernandes, C. Santos, N. Lima. 2014. Synthesis, characterization and antifungal activity of chemically and fungal-produced silver nanoparticles against Trichophyton rubrum. J. Appl. Microbiol., 117(6): 1601-1613.

Pirtarighat. S., M. Ghannadnia, S. Baghshahi. 2019. Green synthesis of silver nanoparticles using the plant extract of Salvia spinosa grown in vitro and their antibacterial activity assessment. $J$.

Nanostruct. Chem., 9(1): 1-9.

Ponarulselvam. S., C. Panneerselvam, K. Murugan, N. Aarthi, K. Kalimuthu, S Thangamani. 2012.Synthesis of silver nanoparticles using leaves of Catharanthus roseus Linn. G. Don and their antiplasmodial activities. Asian. Pac. J. Trop. Med., 2(7): 574-580.

Prusinowska. R., K. Śmigielski, A. Stobiecka, A. Kunicka-Styczyńska.
2016. Hydrolates from lavender (Lavandula angustifolia)-their chemical composition as well as aromatic, antimicrobial and antioxidant properties. Nat. Prod. Res., 30(4): 386-393.

Qayyum. A., T. Malik, S.H. Ali, M. Mushtaq, S.A. Ali. 2020. Rosemarinus officinalis Mediated Synthesis of Silver Nanoparticles and its Activity against Pathogenic Fungal Strains. Trop. J. Nat. Prod. Res., 4(6): 249-254.

Saji. V.S., H.C. Choe, K.W. Yeung. 2010. Nanotechnology in biomedical applications: a review. Int. J. Nano. Biomat., 3(2): 119-139.

Terzieva. S., K. Velichkova, N. Grozeva, N. Valcheva, T. Dinev. 2019. Antimicrobial activity of Amaranthus spp. extracts against some mycotoxigenic fungi. Bulg. J. Agric. Sci., 25: 3.

Veerasamy, R., Xin, T Z. Gunasagaran, S. Xiang, T.F.W. Yang, E. F. C. Jeyakumar, N. \& Dhanaraj, S. A. 2011. Biosynthesis of silver nanoparticles using mangosteen leaf extract and evaluation of their antimicrobial activities. J. Saudi Chem. Soc., 15(2): 113-120.

Zhu. X., H. Zhang, R. Lo. 2004. Phenolic compounds from the leaf extract of artichoke (Cynara scolymus L.) and their antimicrobial activities. J. Agr. Food. Chem., 52(24): 7272-7278. 